Digital Press Social Sciences and Humanities

The Effect of Internal Minor Stress on Marital Satisfaction in Indonesian Intercultural Couples

Dian Wisnuwardhani and Natazsa Octria Putri

Proceeding of The 10th International Conference of Indigenous and Cultural

Psychology 2019

Kwartarini Wahyu Yuniarti, Donald H. Saklofske, Rosnah Ismail, Saadi Lahlou (eds) 


\title{
The Effect of Internal Minor Stress on Marital Satisfaction in Indonesian Intercultural Couples
}

\author{
Dian Wisnuwardhani* \& Natazsa Octria Putri \\ Universitas Indonesia, Faculty of Psychology, 16424, Depok, Jawa Barat, Indonesia \\ *e-mail: dianwisnu15@gmail.com
}

\begin{abstract}
Intercultural couples face cultural conflicts in their marriage, resulting in internal minor stress. Stress as a dyadic phenomenon - commonly found in marriage - affects both individuals involved in the relationship. As a result, couples experience low levels of marital satisfaction. Forty-five intercultural couples from Jakarta, Bogor, Depok, Tangerang, Bekasi Bandung, and Pekanbaru completed this study. The highlight of this study was the use of the Actor-Partner Interdependence Model in the data analysis, using the APIM_SEM application. The result from this study implied that internal minor stress affected marital satisfaction at an individual level, however, no significant effects were found in the partner-effect.
\end{abstract}

\section{Keywords}

actor-partner interdependence model, dyadic stress, marital satisfaction, internal minor stress, intercultural couples

\section{Introduction}

A survey was done by Wang (2012) from the Pew Research Center showed that intercultural marriage is growing rapidly in the United States. In Indonesia, data regarding intercultural married citizens was not yet provided by Badan Pusat Statistik (BPS). However, BPS noted there were 1.300 ethnicities in Indonesia (Na'im \& Syaputra, 2011) which may result in intercultural marriage, especially with the rise of urbanization across the country. Intercultural marriage can be defined as a marriage between two persons coming from different backgrounds such as race, region, ethnicity, or national origin (Sullivan \& Cottone, 2006). The intercultural marriage in this study focused on the marriage of two persons representing different ethnicities.

Compared to intracultural marriage, studies have found that intercultural marriage has higher divorce rates and lower levels of marital satisfaction (Fu, Tora, \& Kendall, 2001; Olson, DeFrain, \& Skogrand, 2011). Several studies proposed the reason behind these findings is that intercultural couples face bigger stressors in their relationship (Bustamante, Nelson, Henriksen, \& Monakes, 2011; Crippen \& Brew, 2013; Fu et al., 2001), resulting in low levels of marital satisfaction or perhaps, divorce. On the other hand, according to Lee, Balkin, and Fernandez (2017), intercultural marriages are relatively more stable and satisfying. Individuals in intercultural marriages were found to be assertive in addressing their problems and practiced dyadic coping (Lee et al., 2017), therefore improving their relationship quality. To conclude, past studies show diverse results regarding intercultural couples' marital satisfaction.

Marital satisfaction is defined as one's subjective evaluation of one's marriage or one's partner (Craighead \& Nemeroff, 2001). Generally, marital satisfaction is influenced by marriage duration, the number of children, and socioeconomic status (Jose \& Alfons, 2007). Undoubtedly, these factors can be found to influence intercultural marriage. However, according to Skowrónski et al. (2014), cultural differences (e.g. different values, norms, attitudes) between intercultural couples are added factors that affect their marital satisfaction. Internal strains originating from cultural differences may take place between individuals.

Such differences, according to Holzapfel, Randall, Tao, and Iida (2018), could manifest as internal minor stress. Internal minor stress is caused by daily minor problems within the marriage (Randall \& Bodenmann, 2017), such as having different attitudes concerning life and relationship, partner's insufficient behavior, also the unsatisfactory distribution of household duties. Based on a qualitative study done by Bustamante et al. (2011), facing different beliefs about the involvement of each other's extended family, different cultural expectations regarding gender roles, or different views on childbearing 
practices are common stressors that affect intercultural couples' marital satisfaction. Moreover, as cultures help to shape different communication styles, intercultural couples often come to misunderstandings (Kim, Prouty, \& Roberson, 2012).

Compared to external stress, internal stress was found to have a stronger effect on marital satisfaction. According to Bodenmann, Ledermann, and Bradburry (2007), external stressors affect marital satisfaction through mediating processes, whereas internal stressors directly erode individuals' marital satisfaction. Several studies have proved the negative associations between internal stress, specifically minor internal stress, on relationship satisfaction (Bodenmann, 2005; Holzapfel et al., 2018). Furthermore, stressors that lasted over time (within 12 months) were found to give a larger impact on relationship satisfaction (Bodenmann, 2005). Notably, couples may experience stress long after the initial stressor occurred (Holzapfel et al., 2018). Therefore, these findings highlight the need for this study to examine the internal minor stress intercultural couples face over time and its associations on marital satisfaction.

According to the systematic-transactional model (STM) (Bodenmann, 1997), stress is a dyadic phenomenon in romantic relationships due to the couples' interdependence. With this model, stress has a cross-over effect on marital satisfaction. In other words, when A experiences stress from facing different cultural expectations with his/her partner, lower levels of marital satisfaction will not only be found in A (actor-effect) but also in A's partner (partner-effect). STM suggests that collecting data as dyadic may help to understand the actor and partner associations between stress and marital satisfaction. Given that intercultural couples potentially face higher levels of internal minor stress, it is important to examine the cross-over effects between both variables in this study. Moreover, Indonesians' communication style may affect the associations between both variables.

Applying the STM, the goal of the present study is to examine the actor-effect and partner-effect between internal minor stress and marital satisfaction in Indonesian intercultural couples. Below is a list of research questions and hypotheses examined in this study.

RQ1: What is the association between one's internal minor stress on one's marital satisfaction? (Actoreffect)

H1: Husbands who experience higher levels of internal minor stress will report lower levels of marital satisfaction.

H2: Wives who experience higher-levels of internal minor stress will report lower levels of marital satisfaction.

RQ 2: What are the associations between one's internal minor stress on one's partner's marital satisfaction? (Partner-effect)

H3: Husbands whose wives experience higher levels of internal minor stress will report lower levels of marital satisfaction.

H4: Wives whose husbands experience higher levels of internal minor stress will report lower levels of marital satisfaction.

\section{Methods}

To participate in this study, participants must be 21 years old or above and have been married for at least one year. Additionally, couples should come from different ethnicities than their spouses and identified themselves as an intercultural couple. This study managed to collect fifty-six intercultural married couples. However, eleven couples either failed to meet certain requirements or failed to complete the study along with their spouses. Thus, only forty-five couples were included in this study. Participants came from Jakarta, Bogor, Depok, Tangerang, Bandung, and Pekanbaru.

Participants were asked to complete a set of questionnaires that measured the level of their internal minor stress specifically caused by their relationship and how satisfied they were with their marriage. Internal minor stress was measured using ten items from the Multidimensional Stress Questionnaire for Couples (MDS-Q) (Bodenmann, Schär, \& Gmelch, 2008). Example of the items includes "different views with your partner in the past 12 months" on a 4-point Likert scale, ranging from 1: (not stressful at all) to 4: (very stressful). Higher scores indicated higher internal minor stress levels. The scale was translated into Bahasa Indonesia, with the internal consistency of $\alpha=.76$.

On the other hand, to measure participants' marital satisfaction, the short version of Couples Satisfaction Index (CSI) by Funk \& Rogge (2007) that contains 16 items was administered. Participants reported how satisfied they were with their marriage on a 6- and 7-point Likert scale. An example item is 
"my relationship with my partner makes me happy". The higher the score, the more satisfied they were. The internal consistency for the Indonesian scale was $\alpha=.93$.

The collected data were analyzed using a web-based application that was specifically designed to analyze the actor and partner interaction, called APIM_SEM (Stas, Kenny, Mayer, \& Loeys, 2018). The application was created by Stas et al. (2018) to simplify analyzing dyadic data with the Actor-Partner Interdependence Model (APIM) using Structural Equation Modeling (SEM) technique. Prior to the data analysis, a test of distinguishability was performed. Dyadic data are prone to interdependence due to the partners' shared experience; hence distinguishability is important (Kashy \& Kenny, 2014). In this study, the data between husbands and wives were found to be distinguishable.

One Actor-Partner Interaction Model (APIM) was performed in this study which examined the association between one's internal minor stress and one's marital satisfaction (actor-effect), as well as the association to their partner's marital satisfaction (partner-effect). Marriage duration, the number of children, husband's income, and wives' income were controlled variables.

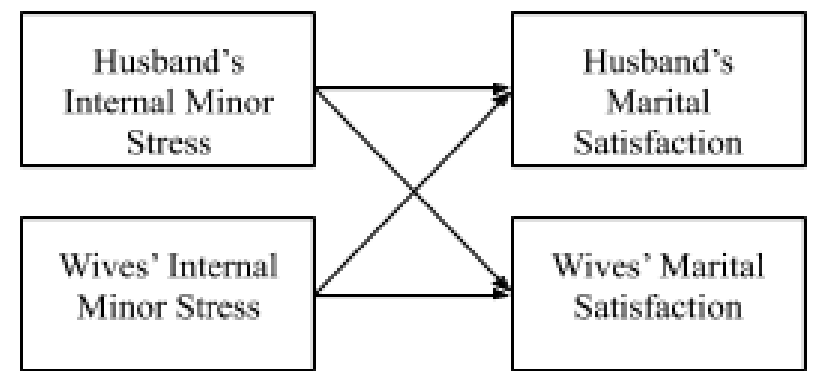

Fig. 1 Conceptual model

\section{Results}

A total of 46 couples returned the questionnaires distributed to them, but only 45 ( Mives $_{\text {wive }}=47.74$ years; Mhusband's age $=50.33$ years) data were analyzed as one couple did not return the questionnaires as a pair. We found that all participants practice the same religion, except for one couple. All couples reported having at least one child in the family. On average, participants in this study are categorized as middle-income families. Participants' marriage duration range between 1 to 33 years, with the average duration of marriage being 19.44 years $(S D=8.64$ years $)$.

Overall, participants reported low levels of internal minor stress and high levels of marital satisfaction. Scores for internal minor stress range between 10 - 40. In this study, wives experience slightly higher levels of stress than husbands. The levels of stress are relatively small, nonetheless. On the other hand, the maximum score for marital satisfaction is 81. As seen in Table 1, participants reported high levels of marital satisfaction, ranging from 61 to 68 on average for both wives and husbands.

Table 1 Mean differences for main variables

\begin{tabular}{ccccc}
\hline & \multicolumn{2}{c}{ Husbands } & \multicolumn{2}{c}{ Wives } \\
\cline { 2 - 5 } & $M$ & $S D$ & $M$ & $S D$ \\
\hline $\begin{array}{c}\text { Internal Minor } \\
\text { Stress }\end{array}$ & 15.13 & 5.39 & 17.20 & 2.93 \\
$\begin{array}{c}\text { Marital } \\
\text { Satisfaction }\end{array}$ & 68.42 & 9.41 & 61.38 & 14.63 \\
\hline
\end{tabular}


Table 2 Actor-partner interdependence model analysis

\begin{tabular}{|c|c|c|c|c|c|c|}
\hline & \multicolumn{3}{|c|}{ Husbands Marital Satisfaction } & \multicolumn{3}{|c|}{ Wives Marital Satisfaction } \\
\hline & $B$ & $S E B$ & $\beta$ & $B$ & SE B & $\beta$ \\
\hline Actor Internal Minor Stress & $-0.91^{*}$ & 0.36 & -0.23 & $-1.04^{*}$ & 0.44 & -0.47 \\
\hline $\begin{array}{l}\text { Partner Internal Minor } \\
\text { Stress }\end{array}$ & -0.39 & 0.29 & -0.18 & -0.72 & 0.53 & -0.33 \\
\hline $\mathrm{R}$ & .436 & & & .363 & & \\
\hline
\end{tabular}

We found support for $\mathrm{H} 1$ and $\mathrm{H} 2$ on negative associations between one's internal minor stress and one's marital satisfaction. The interaction between husbands' internal minor stress and their marital satisfaction was found to be significant $(b=-.91, p=.11)$. In line with this finding, there was also a significant effect of wives' internal minor stress on their marital satisfaction $(b=-1.4, p=.18)$.

$\mathrm{H} 3$ and $\mathrm{H} 4$ that proposed partner effect associations between the two variables was not supported in this study. The interaction between wives' internal minor stress and their husbands' marital satisfaction was not statistically significant $(b=-.39, p=.18)$. For husbands' internal minor stress on their wives' marital satisfaction, the interaction was also found to be not significant $(b=-.72, p=.18)$.

\section{Discussion}

Intercultural couples, compared to intracultural couples, are prone to higher levels of internal minor stress due to their cultural differences (Bustamante et al., 2011; Holzapfel et al., 2018; Skowroński et al., 2014). Applying Bodenmann's (1997) Systematic-Transactional Model (STM), this study examined the cross-over effect of internal minor stress on marital satisfaction. Given that intercultural couples are prone to higher levels of internal minor stress due to their cultural differences, it was expected that they would report high levels of internal minor stress and low levels of marital satisfaction. Further, considering that married couples tend to be highly interdependent, the negative effects of internal minor stress would influence both partners - named actor-effect and partner-effect (Bodenmann, 1997; Kashy \& Kenny, 2014). However, the finding in this study suggests no cross-over effect between both variables. Said differently, one's internal minor stress only affects one's marital satisfaction (actor-effect).

Inconsistent with prior research (Falconier, Nussbeck, Bodenmann, Schneider, \& Bradbury, 2015; Holzapfel et al., 2018; Randall \& Bodenmann, 2017), no significant partner-effect was found between internal minor stress and marital satisfaction in this study. This finding suggests that intercultural couples in Indonesia are not able to communicate the problems, pressure, or stress that they are feeling toward their partner. Therefore, their partners fail to acknowledge the stress they were under and make no effort to make things better. People from collectivistic cultures, such as those from Indonesia, prefer to avoid conversations about their feelings (Hiew, Halford, Vijver, R., \& Liu, 2016) and keep things to themselves. Moreover, Indonesians tend to be judgemental about others based on their ethnicities (Subandi, 2008). They believe that culture shapes an individual and cannot be changed. This belief leads Indonesian intercultural couples to be hesitant about having open communication with their partner.

According to Ledermann, Bodenmann, Rudaz, and Bradburry (2010), couples that actively engage in open communication within their relationship report better relationship quality. Maintaining a satisfying marriage is important, especially when facing stress. With this finding, it is suggested for Indonesian intercultural couples to encourage one another to be vocal. Allowing one's partner to know what one is going through will do more good than harm. By engaging in open communication, couples may find a way to solve the problems they did not know they had inside their relationship together.

\section{Conclusions}

From this study, it can be concluded that there is a negative actor-effect between internal minor stress on marital satisfaction. Contrary to prior research, no significant effect was found on the partner effect. In other words, when A experiences internal minor stress due to cultural differences between his or her 
partner, A's marital satisfaction decreases. The stress that A is under does not affect his or her partner's marital satisfaction in any way.

This study has a few strengths. First, the Actor-Partner Interdependence Model allowed the researchers to examine the cross-over effect between the two variables and develop a better understanding of Indonesian intercultural marriage. Second, this study managed to collect participants from diverse cultural backgrounds. West-Indonesia, Middle-Indonesia, and also East-Indonesia were all represented in this study. Lastly, the measures in this study performed desirable reliability and validity of the sample.

There are also some limitations to this study. The majority of participants reported low levels of internal minor stress and high levels of marital satisfaction, making the generalization of this study limited. This might be due to the fact that most participants had been married for a long time and has had time to adjust their roles as husbands and wives, or fathers and mothers (Wisnuwardhani \& Mashoedi, 2012). Lastly, the collected data in this study was cross-sectional. It is strongly suggested for future research to conduct a longitudinal design to investigate the interactions between internal minor stress and marital satisfaction more accurately. To build upon the research questions examined in this study, a longer period in conducting research is also strongly suggested.

\section{References}

Bodenmann, G. (1997). Dyadic Coping: A Systematic-Transactional View of Stress and Coping Among Couples: Theory and Empirical Findings. European Review of Applied Psychology, 47(2), 137-140.

Bodenmann, G. (2005). Dyadic Coping and Its Significance for Marital Functioning. Couples Coping with Stress: Emerging Perspectives on Dyadic Coping, 1(1), 33-50. https://doi.org/10.1037/11031-002

Bodenmann, G., Ledermann, T., \& Bradbury, T. (2007). Stress, Sex, and Satisfaction in Marriage. Personal Relationships, 14, 551-569. https://doi.org/10.1111/j.1475-6811.2007.00171.x

Bodenmann, G., Schär, M., \& Gmelch, S. (2008). Multidimensional Stress Questionnaire for Couples (MDS-Q) [Unpublished questionnaire].

Bustamante, R., Nelson, J., Henriksen, R., \& Monakes, S. (2011). Intercultural Couples: Coping with CultureRelated Stressors. The Family Journal (Alexandria, Va.), 19(2), 154-164. https://doi.org/10.1177/1066480711399723

Craighead, W. E., \& Nemeroff, C. B. (Eds.). (2001). The Corsini encyclopedia of psychology and behavioral science (Vol. 3). New York: Wiley.

Crippen, C., \& Brew, L. (2013). Strategies of Cultural Adaption in Intercultural Parenting. The Family Journal (Alexandria, Va.), 21(3), 263-271. https://doi.org/10.1177/1066480713476664

Falconier, M. K., Nussbeck, F., Bodenmann, G., Schneider, H., \& Bradbury, T. (2015). Stress from Daily Hassles in Couples: Its Effects on Intradyadic Stress, Relationship Satisfaction, and Physical and Psychological Well-Being. Journal of Marital and Family Therapy, 41(2), 221-235. https://doi.org/10.1111/jmft.12073

Fu, X., Tora, J., \& Kendall, H. (2001). Marital Happiness and Inter-Racial Marriage: A Study in A Multi-Ethnic Community in Hawaii. Journal of Comparative Family Studies, 32(1), 47-60.

Funk, J. L., \& Rogge, R. D. (2007). Testing The Ruler with Item Response Theory: Increasing Precision of Measurement for Relationship Satisfaction with The Couples Satisfaction Index. Journal of Family Psychology, 21(4), 572. https://doi.org/10.1037/0893-3200.21.4.572

Hiew, D. N., Halford, W. K., Vijver, V. D., R., F. J., \& Liu, S. (2016). Communication and Relationship Satisfaction in Chinese, Western, and Intercultural Chinese-Western Couples. Journal of Family Psychology, 30(2), 193-202. https://doi.org/10.1037/fam0000144 
Holzapfel, J., Randall, A. K., Tao, C., \& Iida, M. (2018). Intercultural Couples’ Internal Stress, Relationship Satisfaction, and Dyadic Coping. Interpersona: An International Journal on Personal Relationships, 12(2), 145-163. https://doi.org/10.5964/ijpr.v12i2.302

Jose, O., \& Alfons, V. (2007). Do Demographics Affect Marital Satisfaction? Journal of Sex \& Marital Therapy, 33(1), 73-85. https://doi.org/10.1080/00926230600998573

Kashy, D., \& Kenny, D. (2014). The Analysis of Data from Dyads and Groups. In H. T. Reis \& C. M. Judd (Eds.), Handbook of Research Methods in Social Psychology (pp. 589-607). Cambridge University Press.

Kim, H., Prouty, A., \& Roberson, P. (2012). Narrative Therapy with Intercultural Couples: A Case Study. Journal of Family Psychotherapy, 23(4), 273-286. https://doi.org/10.1080/08975353.2012.735591

Ledermann, T., Bodenmann, G., Rudaz, M., \& Bradbury, T. N. (2010). Stress, Communication, and Marital Quality in Couples. Family Relations, 59(2), 195-206. https://doi.org/10.1111/j.1741-3729.2010.00595.x

Lee, S., Balkin, R. S., \& Fernandez, M. A. (2017). Asian Intercultural Marriage Couples in The United States: A Study in Acculturation and Personality Traits. The Family Journal, 25(2), 164-169. https://doi.org/10.1177/1066480717697951

Na'im, A., \& Syaputra, H. (2011). Kewarganegaraan, Suku Bangsa, Agama Dan Bahasa Sehari-Hari Penduduk Indonesia Hasil Sensus Penduduk 2010. In Retrieved February. Retrieved from http://demografi.bps.go.id/phpfiletree/bahan/kumpulan_tugas_mobilitas_pak_chotib/Kelompok_1/Referen si/BPS_kewarganegaraan_sukubangsa_agama_bahasa_2010.pdf

Olson, D., DeFrain, J., \& Skogrand, L. (2011). Mariages and Families: Intimacy, Diversity, and Strengths (7th ed.). New York: McGraw-Hill.

Randall, A. K., \& Bodenmann, G. (2017). Stress and Its Associations with Relationship Satisfaction. Current Opinion in Psychology, 13, 96-106. https://doi.org/10.1016/j.copsyc.2016.05.010

Skowroński, D., Ying Cherie, T. S., Fernandez, T. M., Fong Tay Danx, D., Ho Wen Wan, M., \& Waszyńska, K. (2014). Introductory Analysis of Factors Affecting Intercultural Couples in the Context of Singapore. Studia Edukacyjne, 263-268. https://doi.org/10.14746/se.2014.30.15

Stas, L., Kenny, D. A., Mayer, A., \& Loeys, T. (2018). Giving Dyadic Data Analysis Away : A User-Friendly App for Actor-Partner Interdependence Models. Personal Relationships, 25(1), 103-119. https://doi.org/10.1111/pere.12230

Subandi, M. A. (2008). Ngemong: Dimensi Keluarga Pasien Psikotik di Jawa. Jurnal Psikologi, 35(1), $62-97$.

Sullivan, C., \& Cottone, R. (2006). Culturally Based Couple Therapy and Intercultural Relationships: A Review of The Literature. The Family Journal, 14(3), 221-225. https://doi.org/10.1177/1066480706287278

Wang, W. (2012). The Rise of Intermarriage : Rates, Characteristics Vary by Race and Gender. Retrieved from https://www.pewresearch.org/wpcontent/uploads/sites/3/2012/02/SDT-Intermarriage-II.pdf

Wisnuwardhani, D., \& Mashoedi, S. F. (2012). Hubungan Interpersonal. Jakarta Selatan: Salemba Humanika. 